\title{
An Experimental Study Carried on Rotary Ultrasonic Machining on Fiber Reinforced Polymer Composites \\ Rounak Nuwal, Vikash Gautam
}

Mechanical Engineering Department, Swami Keshvanand Institute of Technology, Management and Gramothan, Jaipur, 302017 (INDIA)

Email: rknuwal14021997@gmail.com, gautam.mnitj@gmail.com

Received 18.08.2021, received in revised form 10.09.2021, accepted 17.09.2021

doi: $10.47904 / I J S K I T \cdot 11.2 .2021 .71-76$

\begin{abstract}
Rotary Ultrasonic Machining (RUM) is a productive and successful tool used for cutting and machining of fiber-reinforced polymer composites. Fiber-reinforced polymer composites have great applications which have been extensively used in aircraft workings, marine, automotive components and sporting goods. The primary machining operation is surface machining which is the most recurrently employed process on fiber-reinforced composites. However, some challenges like rough surface quality, short tool life, low machining precision and rough edges have not yet discover general applications. The ultrasonic frequency and amplitude both affect the ultrasonic vibrations. Different input parameters such as feed rate, tool rotation speed, depth of cut and ultrasonic power affect on output parameters such as removal rate of material, tool wear and surface roughness which have been studied in this research. The available literature on different machining parameters help in finding research gap in rotary ultrasonic machining process. The consequences of input machining parameters on material removal rates and surface roughness are the key findings of this research.
\end{abstract}

Keywords: Ultrasonic Machining, Rotary Ultrasonic Machining, Fiber-Reinforced Polymer Composites, Surface Roughness, Material Removal Rate.

\section{INTRODUCTION OF RUM}

The process rotary ultrasonic machining (RUM) was evolved and succeed for improvement on the top of ultrasonic machining (USM). The combination of abrasives particles and liquid coolant is used in USM as an abrasive slurry deliver on the machining surface of work specimen during the operation. But abrasive particles are closely affixed to the tool tip in case of RUM process. In this process, the abrasive particles are made up of diamond dust. Various drawbacks of the USM process have been solved due to this. It is extremely difficult to maintain tight tolerance in USM process because abrasive particles and debris material attempt to degrade the surface of the machined specimen. In RUM process, it is easier to machine surface and create holes with the utilization of diamond particles to enhance the geometrical accuracy and quality. RUM process is the most convenient option for extended applications because it is impossible to provide the abrasive slurry to the workpiece during operations on complex shapes. The
RUM tool is 10 times more efficient than the USM tool in similar machining parameters. As when compared to USM process with RUM process the higher quality surface finish is obtained [1].

This process is a non-traditional hybrid machining technique which contains traditional diamond grinding tool and ultrasonic machining tool to ease the machining process [2] [3]. The diamond abrasive particles are closely bonded on a tool tip which vibrates at a high frequency in vertical direction and machining takes place with the high speed rotating spindle at around $1000 \mathrm{rpm}$. The debris particles are flooded with the help of coolant and the coolant also reduce the temperature of machine tool. This process is fully mechanized so there were no change in materialistic properties observed. Which is why, RUM is used for machining on highly hard and brittle materials. To control the spindle speed a CNC controller is used which is programmable by $\mathrm{G}$ and $M$ codes. This process is also using vatious shapes of tools depending on the usability of the material [4].

\section{INVENTION OF ROTARY ULTRASONIC MACHINE}

The ultrasonic vibration assisted machining of material was initially suggested by R.W. Wood and A.L. Loomis in 1927 [5]. The ultrasonic machining tool was initially patented by L. Balamuth in 1945 [6] and the machine tool was firstly made in 1964 [7]. There are few drawbacks of ultrasonic machining process such as short span of tool life, lower rate of material removal (MRR), surface inaccuracies, abrasive slurry path ways are restricted. So to overcome the drawback of USM, Rotary Ultrasonic Machine was initially discovered at United Kingdom Atomic Energy Authority by Percy Legge in 1964. There he is a technical officer. The RUM process contain rotating tool having diamond particles bonded to the tool tip and the workpiece. To achieve tight tolerance the rotational speed of the tool made the workpiece precisely machined. Different types of tool are used for various machining operations such as drilling, milling, inner and outer surface grinding, slot formation and threading. The rotary ultrasonic machining process also known by different names like ultrasonic drilling [8], ultrasonic grinding and 
ultrasonic twist drilling [2].

\section{FUNCTIONING OF ROTARY ULTRASONIC MACHINE}

Rotary ultrasonic machine system contains ultrasonic spindle head, computer numeric control system and coolant/Lubricant tank [2] [8].
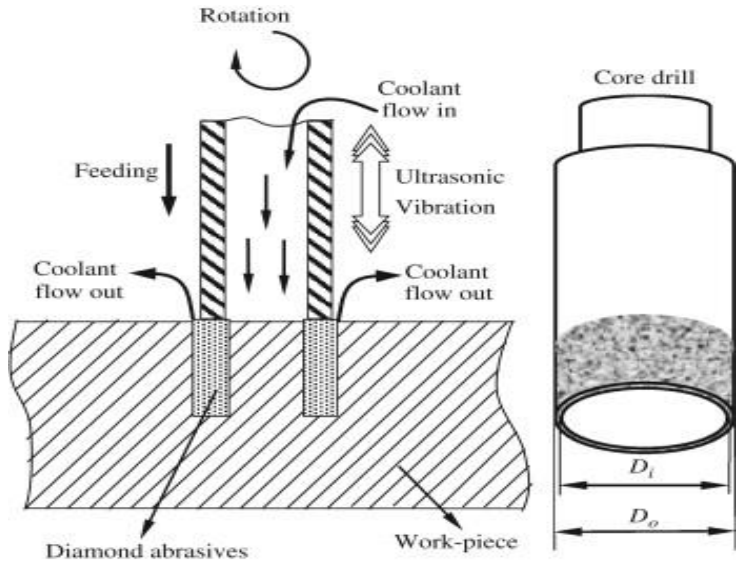

Fig. 1: Diagrammatic interpretation of functioning of RUM [9], [10]

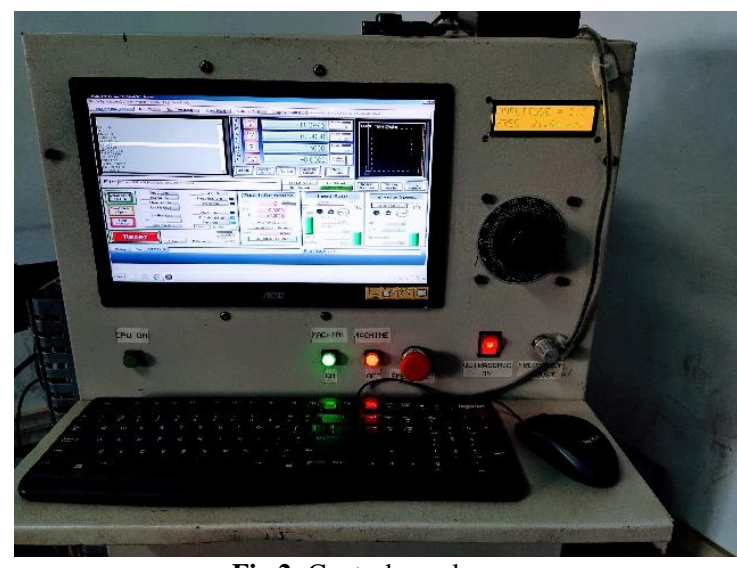

Fig.2: Control panel

The head contains structure which have motor over the spindle to rotate at a high speed (1000 rpm), a transducer, three different stepper motors to move it in $\mathrm{x}, \mathrm{y}, \mathrm{z}$-axis direction, a tool horn and connection to power supply. The transducer is an electronic device which is used to convert electrical energy signals to mechanical vibrations and it works at a high frequency of about $20-25 \mathrm{kHz}$ (tolerance is $+/-2 \%$ ). The transducer is used for rotary ultrasonic machining process for the reason that of high energy conversion efficiency. The horn is a component which provides ultrasonic power transfer from transducer to cutting tool. The essential amplitude is very low therefore amplified with the help of horn situated in the spindle. The tool is made up of diamond which is soldered to this horn.

The coolant/lubricant tank is situated below the machine bed and connected to a pump which circulate it in between tool and workpiece through nozzle.
The computer numeric control is a machine tool used as an automatic machine to control machining operations by means of coded programmed commands. It has a control panel of different electrical and electronic components used to locate the tool. The control panel consist of computer with machining software, an A/D convertor, ultrasonic generator, ultrasonic power regulator, frequency adjust, power on/off switch, digital amplitude and frequency display.

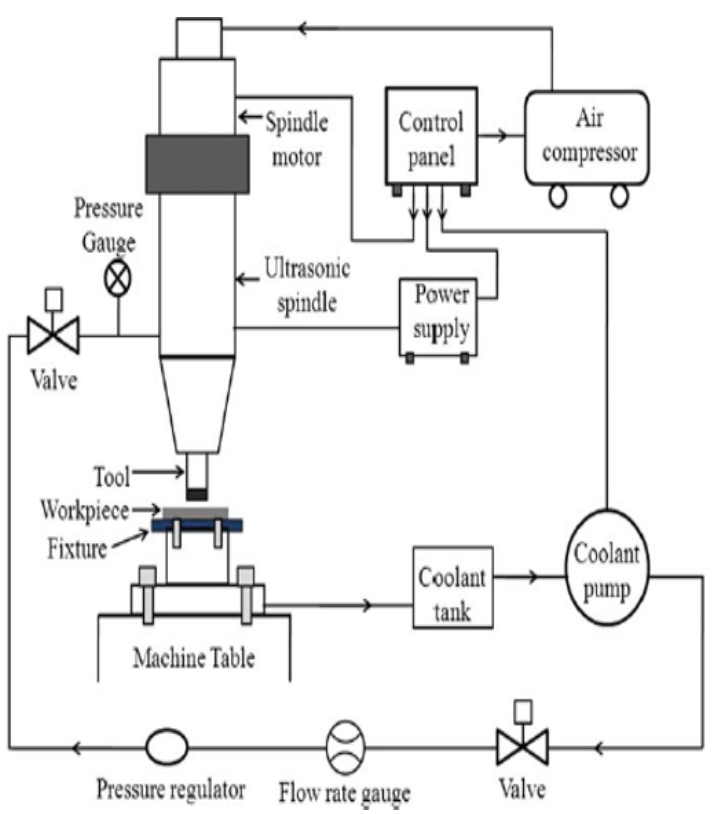

Fig. 3: Flow diagram of RUM system [11]

\section{COMPARISION BETWEEN USM AND RUM}

The ultrasonic machine contains the abrasive particles which spontaneously travel with fluid media, therefore the active abrasive particles are slightly lesser throughout the machining operation. Therefore, while performing operations on ultrasonic machining the MRR is slightly smaller in amount than that on rotary ultrasonic machining where the diamond abrasives are tightly bonded on the tool tip and a great number of abrasive particles create high pressure on workpiece throughout machining operation. MRR also increases as the tool penetration increases. In USM, the used arbitrary abrasive particles were degrade the surface of the workpiece because it strikes back repeatedly on machined surface, which affects geometrical accuracy. In USM, the free abrasive particles also degrade the tool material as it strike back, which results into rapid tool wear. Therefore in USM, it is difficult to meet tight tolerances on workpiece. The abrasive particles used in RUM are of diamond dust which are closely bonded to the tool head. Therefore in RUM, the high pressure exerted on the surface of the workpiece fot machining operation as when compared to USM. As a result of this material removal rate is increased. So in RUM one can vary the ratio of the abrasive 
particles in rotary tool to achieve improved surface finish and tight tolerance [11].

\section{MATERIAL SUBTRACTION TECHNIQUE}

Rotary Ultrasonic Machining is the combination of non-traditional diamond grinding tool and ultrasonic machining tool. Therefore subtraction technique by which material is being removed during the machining process takes place using RUM tool. There are three actions which help in removing material while performing operations on RUM which are as follows: [12]

- Hammering action: The high force of penetration cause crushing of specimen under the pressure of tool vibrations whose frequency is above $20 \mathrm{kHz}$ and this is the main reason of material subtraction by hammering action.

- Abrasion action: The second action of removing material is from diamond abrasive particles takes place by giving rotation to the tool. Therefore it is known as abrasion action.

- Extraction action: Now the last action is to remove debris particles from the machined surface simultaneously by using tool rotation and ultrasonic vibrations. It is also known as withdrawal action.

The below Figure 4 represent diagrammatic interpretation of material subtraction technique using the combination of above mention mechanisms. Therefore rotary ultrasonic machining gives better results than that achieved by individual process such as traditional diamond grinding or ultrasonic machining.

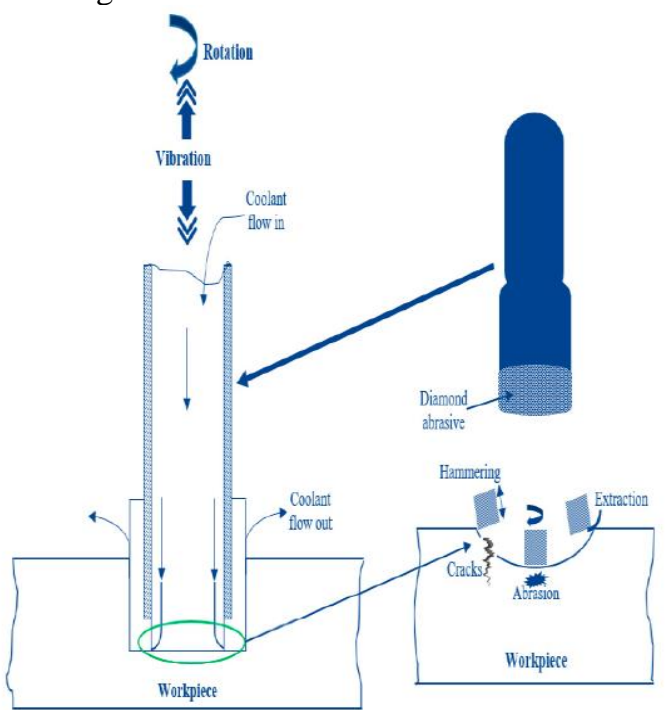

Fig. 4: Diagrammatic interpretation of material subtraction technique in RUM [13]

\section{CONSEQUENCE OF PROCESS VARIABLES ON MRR}

The MRR (Material removal rate) in RUM depends on different process variables for instance frequency, speed, feed rate, ultrasonic power and amplitude. Initially MRR is increased and then slightly decreased when the tool rotation speed was increased. When the feed rate increases the result causes into increase in the material removal rate. And when the depth of penetration of the diamond abrasive particles get enhanced then the material gets start removing at more rapid rate. On same perspective some other researchers also concluded similar results [14]. The improved level of ultrasonic power also resulted with higher Material removal rate. The rise in MRR with an increased spindle speed is due to depth of cut that cause the material removal of the work specimen at moderate rate. These are some process parameters which considered as important for MRR.

In RUM, Ning et al. conducted an experiment on CFRP (carbon fiber reinforced polymer) composites in which feed rate and tool rotation speed are considered the most influential parameters in MRR. And the results compared with grinding process. At higher value of tool rotation speed from $1000 \mathrm{rpm}$ to $5000 \mathrm{rpm}$, MRR first increased from $2.84 \mathrm{~mm}^{3} / \mathrm{s}$ to $2.86 \mathrm{~mm}^{3} / \mathrm{s}$ and then decreased from $2.86 \mathrm{~mm}^{3} / \mathrm{s}$ to $2.85 \mathrm{~mm}^{3} / \mathrm{s}$. When the feed rate is increased from 0.1 $\mathrm{mm} / \mathrm{s}$ to $0.8 \mathrm{~mm} / \mathrm{s}$, MRR is increased from $0.5 \mathrm{~mm}^{3} / \mathrm{s}$ to $4.5 \mathrm{~mm}^{3} / \mathrm{s}$ [15].

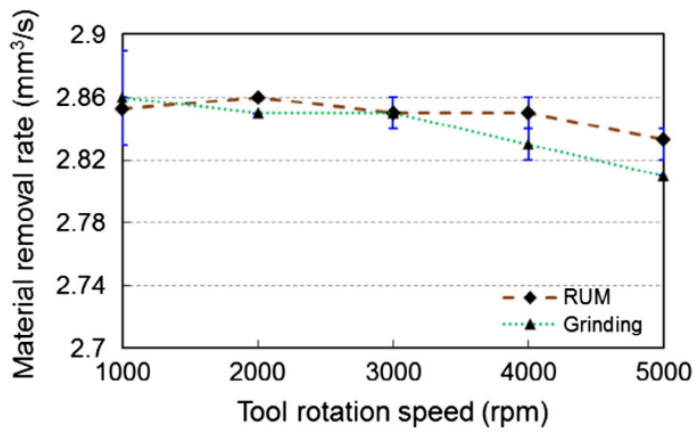

Fig. 5: Variation between MRR and tool rotation speed [15]

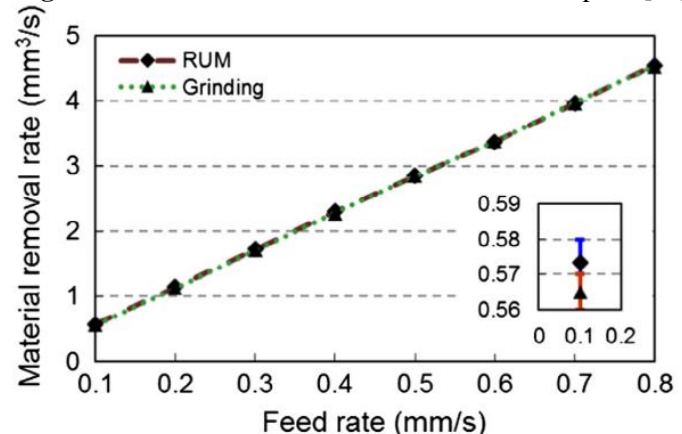

Fig. 6: Variation between MRR and feed rate [15]

\section{CONSEQUENCE OF PROCESS VARIABLES ON SURFACE ROUGHNESS}

The SR (Surface Roughness) of workpiece on RUM depends on different process parameters for instance abrasive size, feed rate, cutting force, frequency, spindle speed and ultrasonic power. When increase in the abrasive size results into increase in 
surface roughness. With increase in the feed rate results an increased in the surface roughness. RUM produces smaller surface roughness under higher ultrasonic frequency. When the tool rotational speed improved or reduction in feed rate lead to an improved and effective interaction time between workpiece and tool contact time and then improved abrasive trajectory overlapping time, leading to smaller surface roughness. When the tool rotation speed increased which resulted into lower surface roughness. And the surface roughness reduced from $1.5 \mu \mathrm{m}$ to $0.5 \mu \mathrm{m}$ when the ultrasonic power gets increased from $30 \%$ to $60 \%$ [14] and at that time the coolant circulation becomes more operational which further creates the machined surface superior in terms of surface roughness [16].

Ning et al. carried out an experiment on CFRP composites in which feed rate and tool rotational speed are considered the most influential parameters in surface roughness. With the increment in tool rotational speed from $3000 \mathrm{rpm}$ to $6000 \mathrm{rpm}$ or decrement in feed rate from $1 \mathrm{~mm} / \mathrm{s}$ to $0.4 \mathrm{~mm} / \mathrm{s}$ results in decrease in the value of surface roughness [17].

Shi et al. carried their evaluation of surface roughness of machined CFRP material using sampling array method. The variability in surface roughness caused by various sampling points is minimized using this evaluation approach. The key sampling no. is $13 \times 13$, and the percentage inaccuracy is found less than $1 \%$, according to the findings. In the feeding direction the $\mathrm{Sa}$ ("arithmetical mean hight of surface roughness") is minimal, whereas in the perpendicular direction to the feed the $\mathrm{Sa}$ is very large. Bending and compression actions cause fiber fracture when the cutting angle is between $90^{\circ}$ and $180^{\circ}$; whereas fiber fracture occurs when bending and tension resulted between $0^{\circ}$ and $90^{\circ}$. Complete fiber breakage occurs after tensile stress crosses its limit value [18].

\section{CONSEQUENCE OF PROCESS VARIABLES ON TOOL WEAR RATE}

The TWR (tool wear rate) significantly depend on the type of abrasive used for the different tool materials. There are many abrasive particles which are used before for instance boron carbide $\left(\mathrm{B}_{4} \mathrm{C}\right)$, silicon carbide $(\mathrm{SiC})$ and aluminum oxide $\left(\mathrm{Al}_{2} \mathrm{O}_{3}\right)$ but now-a-days diamond dust is adapted as an abrasive particle. The rate of tool wear is more when the abrasives of $\mathrm{SiC}$ is used as when compared to that of attained with the usage of $\mathrm{Al}_{2} \mathrm{O}_{3}$. The knoop hardness (use for small brittle material) of the abrasive grains explains the relativeness of the material. And also when the usage of Silicon carbide, consuming 50-60 $\%$ high cutting power as when compared to that of alumina. Therefore, it results into increase in TWR. But by the use of boron carbide as an abrasive grains has lead to a smaller TWR as compared to that of silicon carbide. The diamond as an abrasive gives lower TWR when compared to others [19].

In RUM, a study performed on CFRP material and the result compared to the conventional drilling (CD). The tool wear is depicted in the diagram below at various points around the diamond tool's periphery. It is seen that the chipping dust not attached with the tool of RUM as in case of CD. So better material removal and higher heat conduction result into good tool life. Therefore lower tool wear rate is observed in RUM [20].

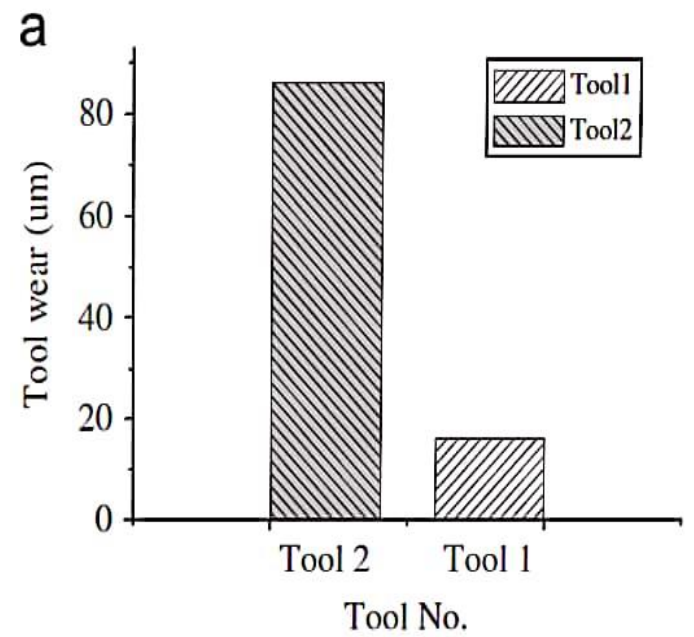

Fig. 7 (a): External tool wear comparision between RUM \& CD [20]

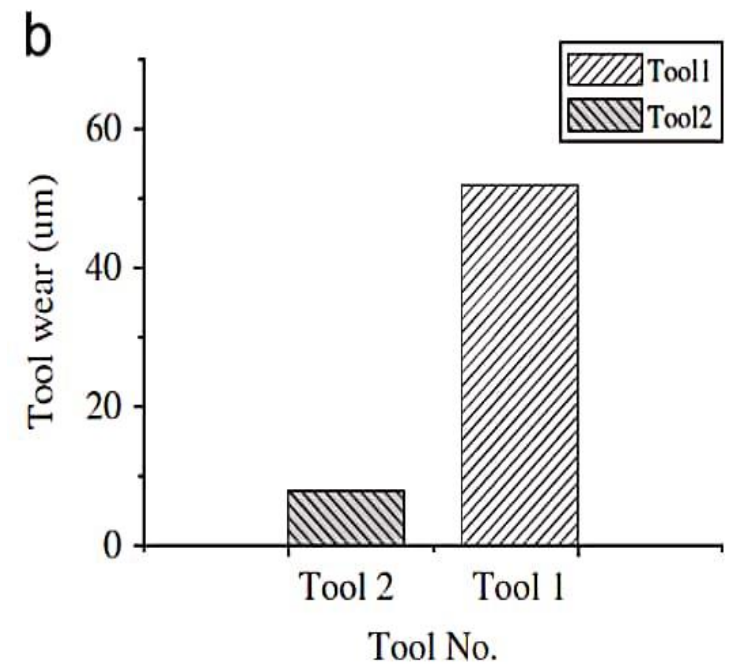

Figure 7 (b): Internal tool wear comparision between RUM \& CD [20] 
Table 1: Comparison of past investigations

\begin{tabular}{|c|c|c|c|}
\hline \begin{tabular}{|l|} 
S. \\
No.
\end{tabular} & Author & Title & Conclusions \\
\hline 1. & Pei et al. & $\begin{array}{l}\text { Rotary ultrasonic } \\
\text { machining of } \\
\text { ceramics: a review }\end{array}$ & $\begin{array}{l}\text { MRR is directly proportional to vibrational amplitude, rotational speed } \\
\text { and inversely proportional to no. of abrasive particles above optimal } \\
\text { value. TWR is directly proportional to frequency and inversely } \\
\text { proportional to amplitude, grit size, bond strength. SR is directly } \\
\text { proportional to frequency, grit size and inversely proportional to diamond } \\
\text { concentration whereas first increased and then decreased in case of } \\
\text { amplitude. }\end{array}$ \\
\hline 2. & Das et al. & $\begin{array}{l}\text { Advancement in } \\
\text { Ultrasonic Machining } \\
\text { for 3D profile Cutting on } \\
\text { ceramics }\end{array}$ & $\begin{array}{l}\text { MRR is directly proportional abrasive particle concentration, abrasives } \\
\text { size and inversely proportional to the profile accuracy. Surface finish is } \\
\text { inversely proportional to the size of the abrasive particle. }\end{array}$ \\
\hline 3. & $\begin{array}{l}\text { Neugebauer } \\
\text { et al. }\end{array}$ & $\begin{array}{l}\text { Ultrasonic application in } \\
\text { drilling }\end{array}$ & $\begin{array}{l}\text { Ultrasonically assisted hybrid machining processes used to outcome with } \\
\text { the issues regarding material removal, chip formation, reliability on } \\
\text { method, stress on tool and exit burrs. Ultrasonic aided machining causes } \\
\text { low cutting forces and easy chip removal. }\end{array}$ \\
\hline 4. & Liu et al. & $\begin{array}{l}\text { A Cutting Force Model } \\
\text { for Rotary Ultrasonic } \\
\text { Machining of Brittle } \\
\text { Materials }\end{array}$ & $\begin{array}{l}\text { Cutting force is directly proportional to feed rate, angle of abrasive } \\
\text { particle and inversely proportional to spindle aped and almost remained } \\
\text { constant with amplitude, abrasive size. }\end{array}$ \\
\hline 5. & Pei et al. & $\begin{array}{l}\text { Rotary ultrasonic } \\
\text { machining for face } \\
\text { milling of ceramics }\end{array}$ & $\begin{array}{l}\text { It is observed that at high feed rate causes tool break and spindle damage. } \\
\text { Scanning electron microscope is utilized to detect surface quality. }\end{array}$ \\
\hline 6. & $\begin{array}{l}\text { Hisham } \\
\text { Alkhalefah }\end{array}$ & $\begin{array}{l}\text { Precise drilling of holes } \\
\text { in alumina ceramic } \\
(\mathrm{Al} 2 \mathrm{O} 3) \text { by rotary } \\
\text { ultrasonic drilling and its } \\
\text { parameter optimization } \\
\text { using MOGA-II }\end{array}$ & $\begin{array}{l}\text { Variation in feed rate causes MRR. Both feed rate and spindle speed } \\
\text { responsible for cylindricity of the hole. Effect of taper angle most in feed } \\
\text { rate then frequency and spindle speed. MOGA-II method is used to find } \\
\text { optimal settings. }\end{array}$ \\
\hline 7. & Churi et al. & $\begin{array}{l}\text { Rotary ultrasonic } \\
\text { machining of titanium } \\
\text { alloy: Effects of } \\
\text { machining variables }\end{array}$ & $\begin{array}{l}\text { Cutting force and SR is inversely proportional to spindle speed, ultrasonic } \\
\text { power and directly proportional to feed rate. First decrease and then } \\
\text { increase in cutting force while increment in ultrasonic power.MRR is } \\
\text { directly proportional to spindle speed, ultrasonic power and feed rate. }\end{array}$ \\
\hline 8. & Ning et al. & $\begin{array}{lr}\text { Rotary } & \text { ultrasonic } \\
\text { machining of } & \text { CFRP: A } \\
\text { comparison } & \text { with } \\
\text { grinding } & \end{array}$ & $\begin{array}{l}\text { In both grinding and RUM, decrease in cutting force, SR and torque } \\
\text { results from increment with } 1000 \text { to } 5000 \mathrm{rpm} \text { and shows opposite } \\
\text { behavior in feed rate from } 0.1 \text { to } 0.8 \mathrm{~mm} / \mathrm{min} \text {. In grinding, MRR is } \\
\text { decreased while in RUM, MRR is increased initially and then decreased } \\
\text { when increment in spindle speed. Feed rate doesnot affect MRR for } \\
\text { grinding and RUM }\end{array}$ \\
\hline 9. & $\begin{array}{l}\text { Ravi Pratap } \\
\text { Singh et al. }\end{array}$ & $\begin{array}{l}\text { Investigation of Process } \\
\text { Responses in Rotary } \\
\text { Ultrasonic Machining of } \\
\text { Al/SiC Composite } \\
\text { Through Designed } \\
\text { Experiments } \\
\end{array}$ & $\begin{array}{l}\text { MRR is higher when increment in feed rate, spindle speed ( } 3000 \text { to } 4200 \\
\text { rpm). SR is lowered when spindle speed increases from } 3000 \text { to } 4200 \text { rpm } \\
\text { and is higher when feed rate increases. Surface finish gets improved when } \\
\text { machine operate at optimal settings for ultrasonic power and coolant flow. } \\
\text { Initially chip thickness is decreased and then increased when feed rate } \\
\text { increases and same relation shows for spindle speed }\end{array}$ \\
\hline 10. & $\begin{array}{l}\text { Haiyan Shi et } \\
\text { al. }\end{array}$ & $\begin{array}{l}\text { Evaluation of surface } \\
\text { roughness based on } \\
\text { sampling array for rotary } \\
\text { ultrasonic machining of } \\
\text { carbon fiber reinforced } \\
\text { polymer composites }\end{array}$ & $\begin{array}{l}\text { The sampling array was chosen at random from the machined area, and } \\
\text { NXN samples were averagely distributed with a } 1 \mathrm{~mm} \text { sampling scale. A } \\
\text { white light interferometer is used to get the sample's three - dimensional } \\
\text { surface texture. The distribution of surface roughness values is extremely } \\
\text { nonuniform, ranging from } 1.2 \mu \mathrm{m} \text { to } 4.0 \mu \mathrm{m} \text {, due to the anisotropic and } \\
\text { non - homogeneous features of CFRP composites. }\end{array}$ \\
\hline 11. & $\begin{array}{l}\text { Jatinder } \\
\text { Kumar and J. } \\
\text { S. Khamba }\end{array}$ & $\begin{array}{l}\text { An Experimental Study } \\
\text { on Ultrasonic } \\
\text { Machining of Pure } \\
\text { Titanium Using } \\
\text { Designed Experiments } \\
\end{array}$ & $\begin{array}{l}\text { Material of the tool considerably affect tool wear rate. Carbide tool causes } \\
\text { more TWR whereas Ti alloy causes less TWR. Same relation shows for } \\
\text { surface roughness. }\end{array}$ \\
\hline 12. & Liu et al. & $\begin{array}{l}\text { Feasibility study of the } \\
\text { rotary ultrasonic } \\
\text { elliptical machining of } \\
\text { carbon fiber reinforced } \\
\text { plastics (CFRP) }\end{array}$ & $\begin{array}{l}\text { Torque and cutting forces decreased using elliptical machining. Material } \\
\text { removal area also increased. It is observed that rods from the core drill } \\
\text { easily ejected. This process of machining increases tool life and enhanced } \\
\text { accuracy of the holes and surface finish. And also at the hole exit, avoids } \\
\text { delamination. }\end{array}$ \\
\hline
\end{tabular}




\section{CONCLUSION}

The rotary ultrasonic machining process is the most convenient option and easy to use technique for machining hard to machine materials having more hardness and brittleness for materials like composites, ceramic, glass, quartz, polymers, optical glass, alloys etc. RUM (rotary ultrasonic machining) is an advance tool to overcome the drawbacks of ultrasonic machining (USM). This paper carried out the conclusions of an investigational study associated with MRR, surface finish and tool life. The key findings are as follows:

1. The diamond impregnated tool is used in RUM as a machining tool which increases the geometrical accuracy and it also produce very high quality holes and better surface even in thicker material.

2. It is being observed that RUM is capable to do same work 10 times more efficiently than that achieved using USM in identical situation.

3. Rotary ultrasonic machining process provide better performances in referred to surface finish, MRR cutting force and edge chipping compared to USM and conventional grinding. MRR is $10 \%$ higher than the other conventional machining processes. Surface roughness can be achieved in $\mu \mathrm{m}$ with an increment in tool rotational speed, increment in the number of diamond abrasives and decrease in feed rate.

4. RUM can have a wide future scope in area of micro machining for creation of micro characteristics for instance complex micro cavity, micro channel, micro hole etc.

5. Rotary ultrasonic machining have horizontal ultrasonic vibrations with diamond tool so both side face and end face of the tool contributed in the machining operation. So both tool-sidesurface and tool-end-surface are mainly used for surface integrity and material removal respectively. Furthermore, the tool end face's interaction with the workpiece material was continuous, whereas the tool side face's interaction with the workpiece material was intermittent.
6. It has been evidently observed that the tool which have higher abrasive concentration can produce higher material removal rates, surface roughness and cutting forces (Fx and Fz).

7. There is a future scope in RUM to investigate some important machining parameters such as temperature of the material while cutting, torque generated, optimization of power consumption because those can affect the materialistic properties.

\section{REFERENCES}

[1] Z. J. Pei, N. Khanna and P. M. Ferreira, "Rotary ultrasonic machining of structural ceramics: a review", Ceramic Engineering and Science Proceedings (1995), Volume 16, Pages 259-278.

[2] P. Legge, "Machining without abrasive slurry", Ultrasonics (1966), Volume 4, no. 3, Pages 157-163.

[3] P. Legge, "Ultrasonic drilling of ceramics", Industrial Diamond Review (1964), Volume 24, no. 278, Pages 2024

[4] S. Das, S. Kumar, G. Kibria, B. Doloi and B. Bhattacharyya, "Advancement in Ultrasonic Machining for 3D Profile Cutting", Advances in Abrasive Based Machining and Finishing Processes, Switzerland, Materials Forming, Machining and Tribology (2020), Pages 44-47.

[5] G. Nishimura, Y. Jimbo and S. Shimakawa, "Ultrasonic machining-Part I", J. Fac. Eng., (1954), Volume 24, no. 3 , Pages 65-100.

[6] L. A. Balamuth, "Method of abrading". British Patent 602801(1), 1945.

[7] L. Rozenberg, V. Kazantsev, L. Makarov and D. Yakhimovich, Ultrasonic cutting, New York: Consultants Bureau, 1964

[8] R. Neugebauer and A. Stoll, "Ultrasonic application in drilling", Journal of Materials Processing Technology (2004), Volume 149, no. 1-3, Pages 633-639.

[9] D. Liu, W. L. Cong, Z. J. Pei and Y. Tang, "A cutting force model for rotary ultrasonic machining of brittle materials", International Journal of Machine Tools \& Manufacture (2012), Volume 52, no. 1, Pages 77-84.

[10] D. Prabhakar, P. M. Ferreira and M. Haselkorn, "An experimental investigation of material removal rates in rotary ultrasonic machining", Transactions of the North American Manufacturing Research Institution of SME, Pullman, Washington, USA (1992), Volume 20, Pages 211-218. 